\title{
Changes in gastric acid secretion assayed by endoscopic gastrin test before and after Helicobacter pylori eradication
}

\author{
K Iijima, S Ohara, H Sekine, T Koike, K Kato, S Asaki, T Shimosegawa, T Toyota
}

\begin{abstract}
Background-It remains controversial whether or not Helicobacter pylori infection causes altered gastric acid secretion. A novel test for evaluating gastric acid secretion (endoscopic gastrin test; EGT) has recently been developed.

Aim-To investigate by EGT the effects of $H$ pylori eradication on the state of gastric acid secretion in patients with peptic ulcer. Methods-Twenty six patients with duodenal ulcer and 33 with gastric ulcer, for all of whom $H$ pylori infection had been documented, were studied by EGT, histological examination of gastric mucosa, and measurement of plasma gastrin levels before and one and seven months after $H$ pylori eradication.

Results-In patients with duodenal ulcer, the mean EGT value before $H$ pylori eradication was higher than that in $\mathrm{H}$ pylori negative controls, but it had decreased significantly seven months after the treatment. In contrast, the mean EGT value of patients with gastric ulcer before $H$ pylori eradication was lower than that in $H$ pylori negative controls, but it had increased one month after the treatment; this was followed by a slight decrease at seven months. In both groups, mean EGT values seven months after the treatment were not significantly different from the mean control value. Conclusions-The reduced acid secretion in gastric ulcer patients and gastric acid hypersecretion in duodenal ulcer patients were both normalised after the clearance of $\mathrm{H}$ pylori.

(Gut 2000;46:20-26)
\end{abstract}

Third Department of Internal Medicine,

Tohoku University

School of Medicine,

Sendai, Miyagi, Japan

K Iijima

S Ohara

H Sekine

T Koike

K Kato

S Asaki

T Shimosegawa

T Toyota

Correspondence to: Dr K Iijima, Third Department of Internal Medicine, Tohoku University School of Medicine, 1-1 Seiryo-machi, Aobaku, Sendai 980-8574, Japan.

Accepted for publication 18 August 1999
Keywords: acid secretion; duodenal ulcer; endoscopic gastrin test (EGT); gastric ulcer; Helicobacter pylori

Since the discovery of Helicobacter pylori, many studies have shown that its eradication markedly decreases the rate of duodenal ulcer (DU) and gastric ulcer (GU) relapse, ${ }^{1-3}$ and $H$ pylori is therefore recognised as an important acquired factor in the pathogenesis of peptic ulcers. However, the mechanism by which this organism promotes the recurrence of ulcers remains unknown. To date, the effects of $H$ pylori on gastric acid secretion, the most important factor for development of peptic ulcer diseases, remain controversial..$^{4-11}$ One reason for the controversy is that most studies have examined a small number of patients only, and direct elucidation of the causal relation requires a comparison of gastric acid secretions before and after $H$ pylori eradication in a large number of patients with peptic ulcer disease. However, as far as we know there have been very few such studies, especially on patients with GU. ${ }^{11}$

Recently we have developed a rapid simple endoscopic method for evaluating gastrin stimulated maximal acid output (endoscopic gastrin test; EGT), the results from which correlate very closely with peak acid output determined by the conventional gastric acid secretory test. ${ }^{12}$ Using EGT, we can perform endoscopic examination and stimulated acid secretory testing simultaneously within about 15 minutes. In this study, we evaluated by EGT the gastrin stimulated acid output in a large number of patients with DU and GU before and after $H$ pylori eradication to clarify the relation between $H$ pylori infection and gastric acid secretion, and compared it in patients with DU and GU.

\section{Subjects and methods}

SUBJECTS

Twenty nine patients with DU and 35 patients with GU in whom $H$ pylori infection had been confirmed were enrolled. Active ulcer disease had been confirmed endoscopically within the six months preceding entry into the study. Patients with both GU and DU were excluded. GUs were located on the lesser curvature of the incisura angularis in 24 patients, in the corpus in 10 patients, and in the antrum in one. $H$ pylori infection status was determined by the rapid urease test and histology. None of the patients had taken non-steroidal antiinflammatory drugs, antibiotics, or proton pump inhibitors within 15 days of study entry. All patients were asked to stop taking $\mathrm{H}_{2}$ blockers at least 48 hours before study entry.

At entry, each patient had upper gastrointestinal endoscopy, which included EGT and biopsies from the antrum and body of the stomach for histological examination and rapid urease test, as well as determination of fasting plasma gastrin concentrations. After this initial assessment, patients received eradication treatment consisting of omeprazole $20 \mathrm{mg}$ a day, metronidazole $500 \mathrm{mg}$ twice a day, and clarithromycin $200 \mathrm{mg}$ twice a day for a week, and $H$ pylori status was redetermined by a combination of histological examination, rapid urease test, and ${ }^{13} \mathrm{C}$-urea breath test one month later. All patients in whom eradication was confirmed at this point had a repeat determination of $H$ pylori infection status seven months later. Upper gastrointestinal endoscopy,

Abbreviations used in this paper: DU, duodenal ulcer; EGT, endoscopic gastrin test; GU, gastric ulcer. 
including EGT, histological examination, and plasma gastrin measurement, was repeated one and seven months after the eradication treatment. Asymptomatic subjects matched for age, sex, and body weight were selected as controls for $H$ pylori positive patients with DU or GU, from the subjects who underwent endoscopy during the study period and were confirmed to be $H$ pylori negative by rapid urease test and histological examination. The study was conducted in accordance with the Helsinki Declaration as revised in Tokyo, and informed consent was obtained from each subject.

ENDOSCOPIC GASTRIN TEST

The technique for performing EGT has been reported previously. ${ }^{12}$ Briefly, after an overnight fast, subjects were injected intramuscularly with tetragastrin (Gastopsin Nippon Kayaku, Tokyo, Japan), $4 \mu \mathrm{g} / \mathrm{kg}$, before endoscopy. Endoscopy was begun about 15 minutes after the tetragastrin injection. After the endoscope had entered the stomach, pooled gastric fluid was aspirated and discarded. Gastric fluid secreted between 20 and 30 minutes after the tetragastrin injection was aspirated and collected under direct visualisation during routine endoscopic examination of the stomach and duodenal bulb. Biopsy specimens were then taken when indicated, and the endoscope was removed. The volume of sample collected over the 10 minute period was recorded, and its $\mathrm{H}^{+}$concentration was determined by titration. The acid output in the 10 minute period was calculated by multiplying the volume by the $\mathrm{H}^{+}$concentration, and the EGT value was expressed as $\mathrm{mEq} / 10 \mathrm{~min}$. We have shown previously that EGT values correlate very closely with peak acid output determined by conventional methods (correlation efficient $=0.92$ ) and have high reproducibility (coefficient of variation $=5.6 \%) .{ }^{12}$

\section{HISTOLOGICAL EXAMINATION}

Biopsy specimens taken endoscopically from the gastric antrum and upper body in the greater curvature were evaluated histologically. Using the Updated Sydney system, the degree of inflammation, activity, and atrophy were scored from 0 to $3 .^{13}$ The inflammation and activity scores were added together to form a gastritis score.

${ }^{13}$ C-UREA BREATH TEST

The ${ }^{13} \mathrm{C}$-urea breath test was performed as previously reported. ${ }^{14}$ Briefly, after a baseline breath sample had been taken, fasting patients were given $100 \mathrm{mg}\left[{ }^{13} \mathrm{C}\right]$ urea in $100 \mathrm{ml}$ water. An additional breath sample was taken 20 minutes after urea administration. Breath samples obtained at baseline and after drug administration were analysed for ${ }^{13} \mathrm{CO}_{2}$ with a mass spectrometer. We determined the cut off value for a positive urea breath test at $2.5 \%$.

GASTRIN DETERMINATION

A fasting blood sample was obtained for gastrin determination, and the plasma stored at $-20^{\circ} \mathrm{C}$. Plasma gastrin concentrations were measured with a radioimmunoassay (Dainabot Co, Tokyo, Japan).
Table 1 Comparison of demographics of patients with Helicobacter pylori infection who also have either duodenal ulcer (DU) or gastric ulcer (GU)

\begin{tabular}{llll}
\hline & $D U$ & $G U$ & p Value \\
\hline Patients (n) & 26 & 33 & \\
Men/women (n) & $18 / 8$ & $28 / 5$ & \\
Age (years) & $35(11)$ & $55(12)$ & $<0.01$ \\
Body weight (kg) & $63(16)$ & $62(10)$ & $\mathrm{NS}$ \\
Serum gastrin (pg/ml) & $104(44)$ & $110(73)$ & $\mathrm{NS}$ \\
EGT value (mEq/10 min) & $5.1(2.7)$ & $2.9(1.8)$ & $<0.01$ \\
\hline
\end{tabular}

Data represent mean (SD). EGT, endoscopic gastrin test.

\section{STATISTICAL METHODS}

The EGT values and gastrin concentrations are expressed as means (SD), and Student's unpaired $t$ test (for unpaired values), and Student's paired $t$ test (for paired values) were used to compare group means. Histological scores were expressed as mean (SD), and the statistical significance of differences in histological scores was determined by the Mann-Whitney test (for unpaired values) and the Wilcoxon rank sum test (for paired values). $\mathrm{p}<0.05$ was considered to be statistically significant.

\section{Results}

PATIENT PROFILES

$H$ pylori eradication was achieved in 26 of 29 patients with DU, and in 33 of 35 patients with GU. All patients in whom $H$ pylori organisms were cleared at one month after eradication treatment remained free of $H$ pylori infection at seven months after the treatment. No patient experienced a relapse during this period. Three patients with DU (two men) and two with GU (both men) in whom $H$ pylori organisms were not cleared were excluded from further study. Table 1 shows details of the remaining subjects. The mean age was higher in the group with GU than in the group with DU, whereas the mean body weight was identical in the two groups.

\section{HISTOLOGICAL EXAMINATION}

Gastritis score

Before eradication, there was no significant difference between the patients with DU and those with GU with regard to the degree of gastritis in the antrum (DU mean, 3.9 (1.0); GU mean, 3.5 (1.0); fig 1A). In contrast, the mean gastritis score in the gastric body of patients with GU was 2.1 (1.1), which is significantly higher than the mean score of $1.3(0.7)$ in patients with DU $(p<0.01)$ (fig 1B). At one month after the eradication, the mean gastritis score in the antrum had decreased significantly to $1.3(0.6)$ in the DU group $(\mathrm{p}<0.01)$ and $1.4(0.5)$ in the GU group $(\mathrm{p}<0.01)$; at seven months after eradication, it showed a slight further decrease in both groups $(1.1(0.4)$ in patients with $\mathrm{DU}$, 0.9 (0.5) in patients with GU). The difference in the mean gastritis score between one and seven months after the eradication was significant only in the GU group $(p<0.01)$. The change in gastritis score in the body after eradication was similar to that in the antrum. The mean gastritis score in the body fell significantly from 2.1 (1.1), the value before eradication, to $0.4(0.5)$ in patients with DU and from 1.3 $(0.6)$ to $0.7(0.5)$ in patients with $\mathrm{GU}$ at one month (both $\mathrm{p}<0.01)$. It fell further to $0.2(0.4)$ 

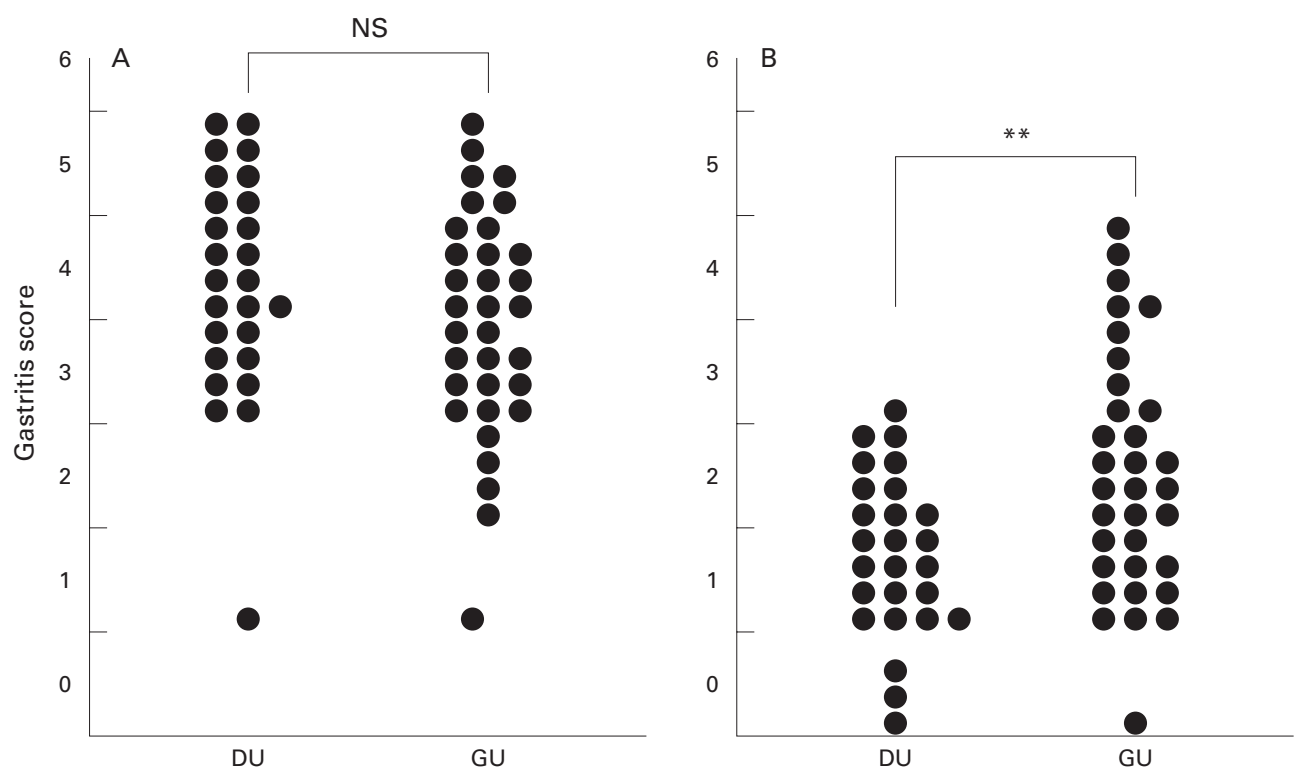

Figure 1 Gastritis scores of the antrum $(A)$ and body (B). Before eradication of H pylori, the mean gastritis score of the antrum was not significantly different between the patients with duodenal ulcer (DU) and those with gastric ulcer (GU), but in the gastric body, it was significantly higher in the patients with $G U$ than in those with $D U .{ }^{\star *} p<0.01 ; N S$, not significant.

in patients with DU and to $0.4(0.5)$ in patients with GU at seven months, but the decreases between one and seven months were not significant in either group (fig 2).

\section{Atrophy score}

Mucosal atrophy was more prevalent in patients with GU than in those with DU in both the antrum and body, whereas antral atrophy was more marked than body atrophy in both patient groups. Before eradication, the mean atrophy score in the antrum of patients with GU was $1.7(0.8)$, and was significantly higher than the mean score of $0.8(0.7)$ in patients with DU $(p<0.01)$ (fig 3A). Similarly, in the body, the mean atrophy score was significantly higher in patients with GU than in

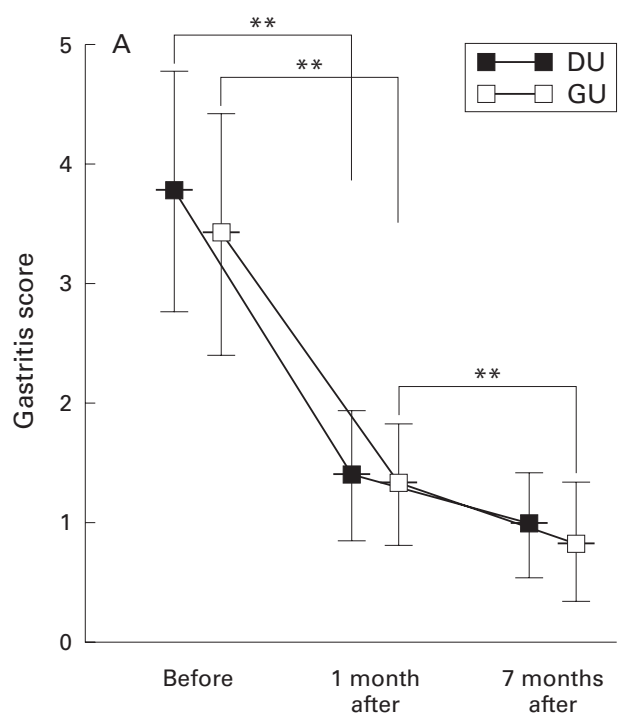

those with DU (0.3 (0.6) and $0.04(0.2)$ respectively; $\mathrm{p}<0.05$; fig $3 \mathrm{~B})$. During follow up after eradication, there was no statistically significant change in the degree of antral or body atrophy in patients with either DU or GU, although there was a trend toward improvement in those with GU (antrum, 1.5 (0.8) at one month, $1.3(1.0)$ at seven months, $\mathrm{p}=0.1$; body, $0.2(0.3)$ at one month, $0.1(0.2)$ at seven months, $\mathrm{p}=0.07$ ) (fig 4 ).

FASTING PLASMA GASTRIN

Before eradication, fasting plasma gastrin concentrations were similar in $H$ pylori positive patients with DU and those with GU (DU, 104 (44) $\mathrm{pg} / \mathrm{ml}$; GU, 110 (73) pg/ml) (table 2), and the concentrations in both groups were

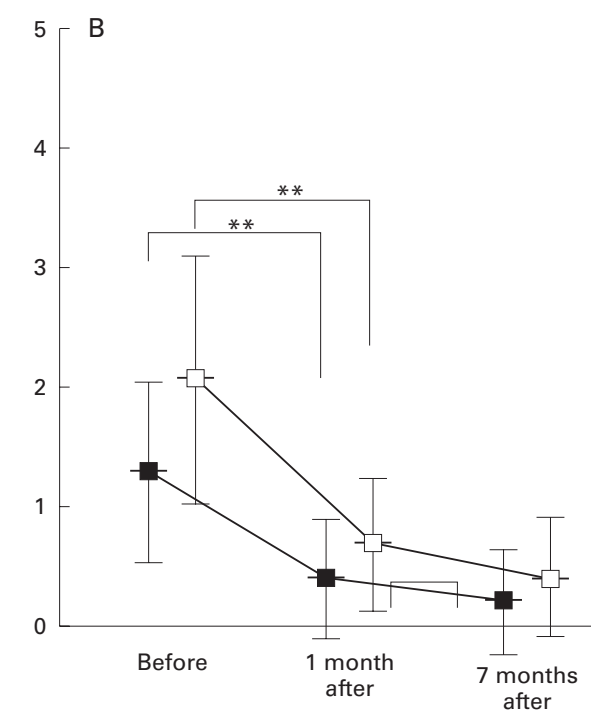

Figure 2 Changes in gastritis score in the antrum $(A)$ and body $(B)$ caused by H pylori eradication. One month after the eradication treatment, the mean gastritis score in the antrum had fallen significantly in the patients with duodenal ulcer $(D U)$ as well as in those with gastric ulcer $(G U)$. Between one and seven months, the value decreased significantly only in those with GU. In the gastric body, the mean gastritis score had decreased significantly in both groups at one month. No further decrease was found in either group between one and seven months after the eradication. Vertical bars represent SD of the mean gastritis score. ${ }^{\star \star} p<0.01$ compared with before. 

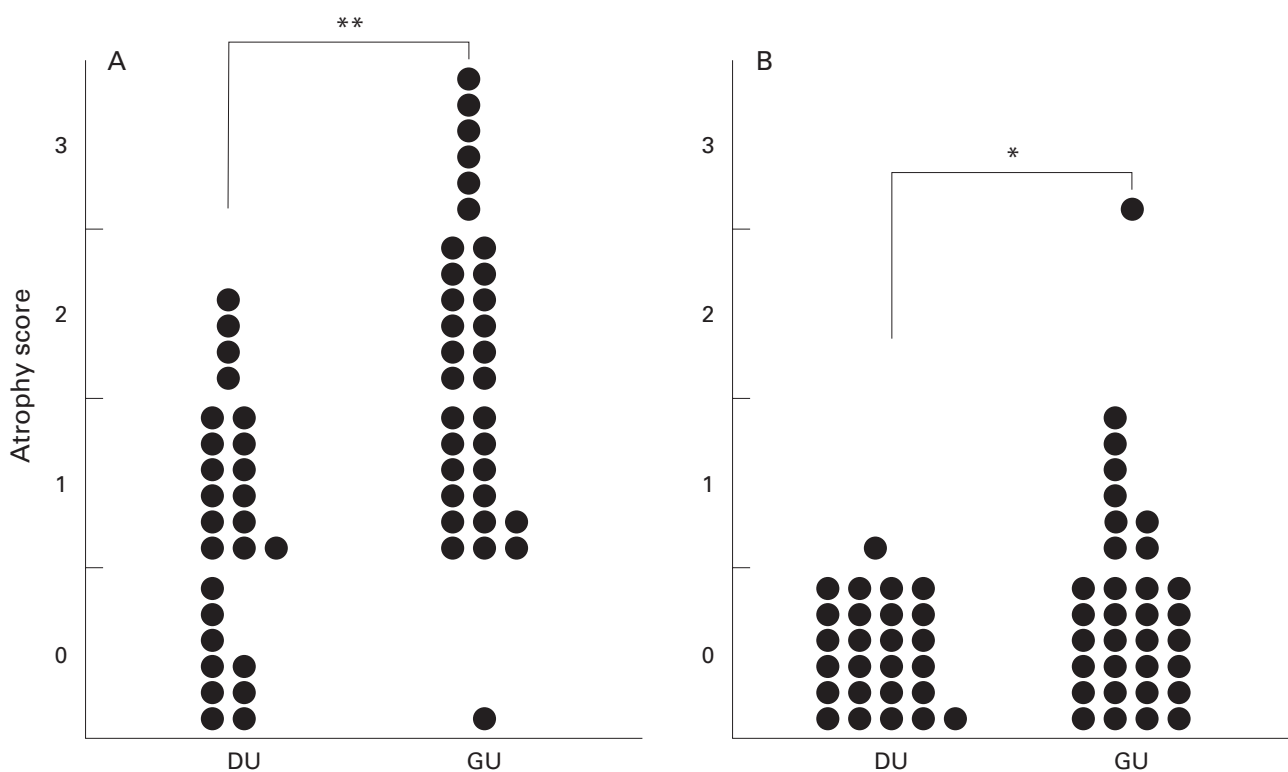

Figure 3 Atrophy scores of the antrum $(A)$ and body $(B)$. Before eradication of $H$ pylori, the mean atrophy score of the antrum in patients with gastric ulcer (GU) was significantly higher than that of patients with duodenal ulcer (DU). Similarly, the mean atrophy score of the gastric body was significantly higher in the patients with $G U$ than patients with DU. ${ }^{\star} p<0.05,{ }^{\star}{ }^{\star} p<0.01$.

significantly higher than those in $H$ pylori negative controls (controls for patients with DU, 62 (16) $\mathrm{pg} / \mathrm{ml}, \mathrm{p}<0.01$; controls for patients with GU, 63 (22) pg/ml, p<0.01). At one month after eradication, the mean gastrin concentrations decreased significantly to $60(14) \mathrm{pg} / \mathrm{ml}$ in patients with DU and to 69 (31) $\mathrm{pg} / \mathrm{ml}$ in those with GU. Neither of these values were significantly different from those in $H$ pylori negative controls. After seven months, there was no significant fall in gastrin concentration in either patient group compared with the one month value (table 2 ).

ENDOSCOPIC GASTRIN TEST

Before eradication, the mean EGT value was significantly higher in patients with DU than in those with GU (5.1 (2.7) v $2.9(1.8) \mathrm{mEq} / 10$

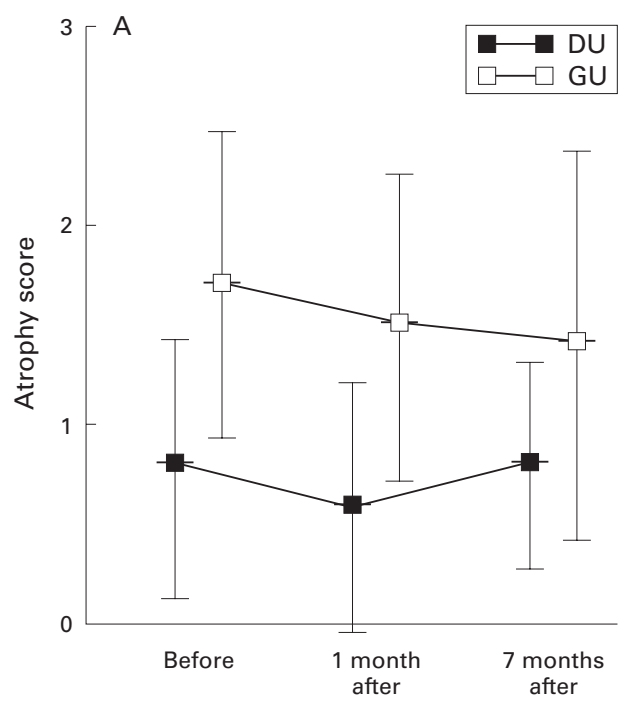

min, $\mathrm{p}<0.01$ ) (table 2). In patients with DU with $H$ pylori infection, the mean EGT value was significantly higher than in $H$ pylori negative controls $(5.1$ (2.7) $v 3.7$ (1.4) $\mathrm{mEq} / 10$ min, $\mathrm{p}<0.01)$. One month after eradication, no significant change was seen in EGT values in the patients with DU (5.2 (2.5) $\mathrm{mEq} / 10 \mathrm{~min})$, whereas it had fallen significantly at seven months after the eradication (from 5.1 (2.7) $\mathrm{mEq} / 10 \mathrm{~min}$ before eradication to 3.9 (1.9) $\mathrm{mEq} / 10 \mathrm{~min}, \mathrm{p}<0.01)$. The value at seven months was not significantly different from that in $H$ pylori negative controls (fig 5, table 2).

In patients with $\mathrm{GU}$ with $H$ pylori infection, the mean EGT value was significantly lower than in $H$ pylori negative controls $(2.9$ (1.8) $v$ 4.1 (1.6) $\mathrm{mEq} / 10 \mathrm{~min}, \mathrm{p}<0.01)$. The mean EGT value of patients with GU with $H$ pylori

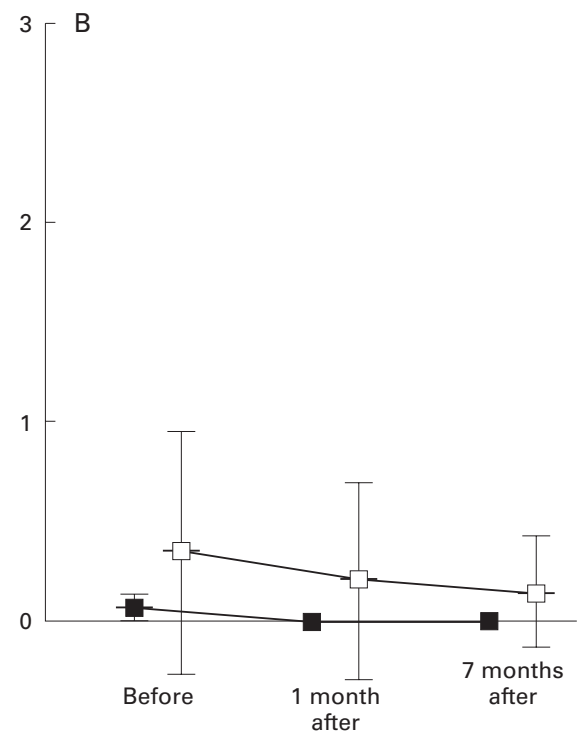

Figure 4 Changes in atrophy score in the antrum $(A)$ and body $(B)$ caused by H pylori eradication. After the eradication, the degree of antral or body atrophy did not change significantly in patients with either duodenal ulcer (DU) or gastric ulcer $(G U)$. Vertical bars represent $S D$ of the mean atrophy score. 
Table 2 Changes in endoscopic gastrin test (EGT) values and serum gastrin before and after Helicobacter pylori eradication

\begin{tabular}{|c|c|c|c|c|c|c|c|c|}
\hline & \multicolumn{4}{|l|}{$D U$} & \multicolumn{4}{|l|}{$G U$} \\
\hline & Before & 1 month & 7 months & Control & Before & 1 month & 7 months & Control \\
\hline Gastrin (pg/ml) & $104(44)$ & $60(14)^{\star \star}$ & $59(11)^{\star \star}$ & $62(16)^{\star \star}$ & $110(73)$ & $69(31)^{\star \star}$ & $64(22)^{\star \star}$ & $63(22)^{\star \star}$ \\
\hline $\mathrm{EGT}(\mathrm{mEq} / 10 \mathrm{~min})$ & $5.1(2.7)$ & $5.2(2.5)$ & $3.9(1.9)^{\star \star}+\dagger$ & $3.7(1.4)^{\star \star}$ & $2.9(1.8)$ & $4.9(2.3)^{\star \star}$ & $4.3(1.9)^{\star \star} \dagger$ & $4.1(1.6)^{\star \star}$ \\
\hline
\end{tabular}

Data are expressed as mean (SD). DU, duodenal ulcer; GU, gastric ulcer.

${ }^{\star \star} \mathrm{p}<0.01$, compared with the value before eradication; $t \mathrm{p}<0.05, t+\mathrm{p}<0.01$ compared with the value at one month.

infection increased significantly from 2.9 (1.8) $\mathrm{mEq} / 10 \mathrm{~min}$ before eradication to $4.9(2.3)$ $\mathrm{mEq} / 10 \mathrm{~min}$ at one month $(\mathrm{p}<0.01)$, and then decreased slightly but significantly to 4.3 (1.9) $\mathrm{mEq} / 10 \mathrm{~min}$ at seven months $(\mathrm{p}<0.05$, compared with the one month value). The mean EGT value at seven months was not signifi-

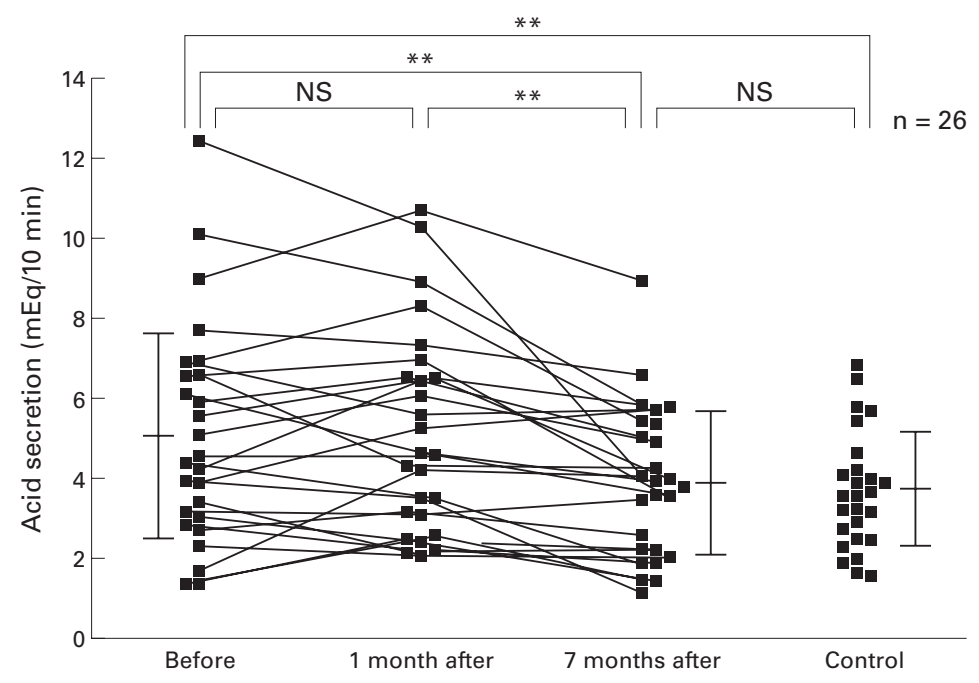

Figure 5 Changes in acid secretion in patients with duodenal ulcer (DU) after H pylori eradication. In the $H$ pylori positive patients with DU, the mean EGT value was significantly higher than that of $H$ pylori negative controls. One month after the eradication, no significant change was found in the EGT value, but it had fallen significantly at seven months after the eradication. The value at seven months was not significantly different from the control value. Vertical bars represent $S D$ of the mean.

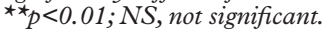

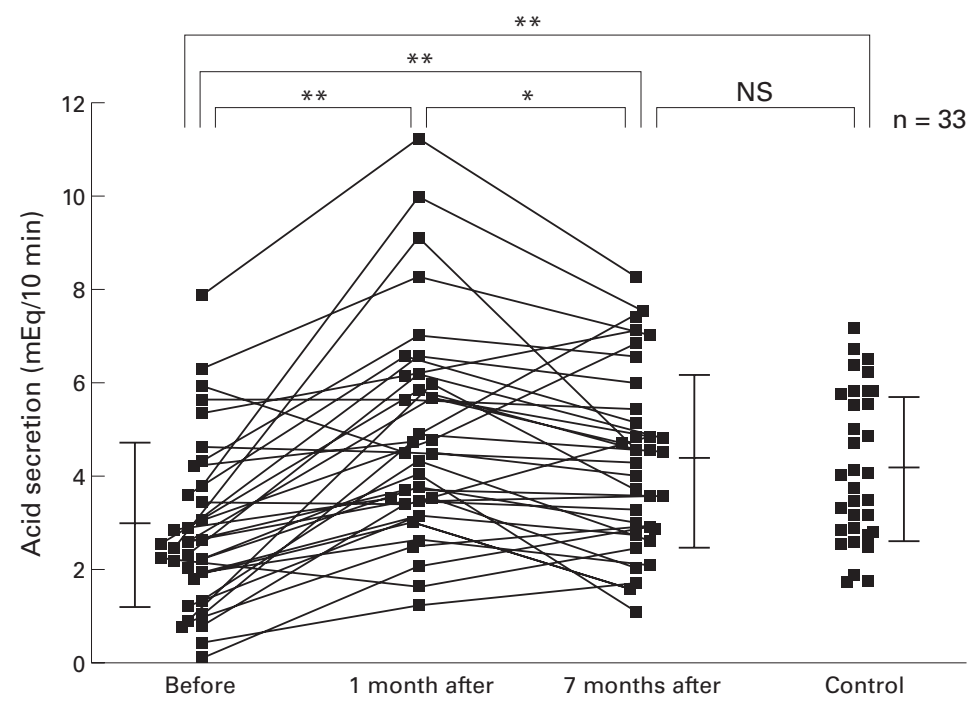

Figure 6 Changes in acid secretion in patients with gastric ulcer $(G U)$ after $H$ pylori eradication. In the $H$ pylori positive patients with $G U$, the mean $E G T$ value was significantly lower than that of $H$ pylori negative controls. One month after the eradication, the mean EGT value increased significantly, and then decreased slightly but significantly at seven months. The value at seven months was not significantly different from the control value, but it was still higher than that before eradication. Vertical bars represent $S D$ of the mean. ${ }^{\star} p<0.05,{ }^{\star *} p<0.01, N S$, not significant. cantly different from that in $H$ pylori negative controls, but was still higher than that recorded before eradication (4.3 (1.9) $v 2.9$ (1.8) $\mathrm{mEq} / 10$ min, $\mathrm{p}<0.01$ ) (fig 6, table 2 ).

\section{Discussion}

In this study, we have shown by EGT that $H$ pylori eradication was accompanied by a decrease in acid secretion in patients with DU, while it actually increased after eradication in patients with GU. Before $H$ pylori eradication, patients with DU had greater acid secretion than $H$ pylori negative normal subjects. This finding is in agreement with a previous report. ${ }^{15}$ On the other hand, in patients with $H$ pylori positive GU, the mean EGT value was significantly lower than that in $H$ pylori negative normal subjects. It has been suggested that acid secretion in patients with GU greatly varies depending on the anatomical location of the ulcers; those in the antrum are associated with hypersecretion and those in the gastric body are associated with hyposecretion. ${ }^{15}{ }^{16}$ In this study, the results for patients with GU are in agreement with our expectations because antral ulceration was seen in only one patient.

One month after eradication, the mean EGT value of patients with DU was unchanged compared with before eradication. Previous studies have shown that basal acid output decreases rapidly after $H$ pylori eradication, apparently in direct association with decreased serum gastrin. ${ }^{6}{ }^{9}$ However, the gastrin stimulated acid output shown by EGT, which reflects the total functional parietal cell mass, was unchanged one month after eradication in our study. ${ }^{4}$ The disparity may be caused by the difference in intervals required to achieve a decrease in the basal and gastrin stimulated acid outputs, as discussed below.

On the other hand, in patients with GU, the mean EGT value had increased rapidly one month after eradication. Recent studies have reported that, although gastric acid secretion was low in $H$ pylori positive patients with gastritis of the corpus, clearance of $H$ pylori organisms rapidly improved the decreased acid secretion. ${ }^{17-19}$ Because body gastritis was more pronounced in patients with GU than in those with DU, in agreement with the findings of others, ${ }^{20} 21$ the acid secretion, which was subnormal before eradication, increased when the gastric inflammation subsided after eradication in patients with GU. The mechanism by which body gastritis inhibits gastric acid secretion is not clear, but inflammatory cytokines such as interleukin-1 or proteins produced by $H$ pylori may be responsible for reversible inhibition of acid secretion. ${ }^{22-24}$ 
Between one and seven months after $H$ pylori eradication, significant decreases in acid secretion were seen in both patients with DU and those with GU. The mechanism of this decreased acid secretion may be related in part to a fall in plasma gastrin, which was commonly observed in association with both diseases. That is, gastrin, which exerts trophic effects not only on parietal cells ${ }^{25}{ }^{26}$ but also on enterochromaffin-like cells, ${ }^{27}$ was suppressed for a long time after the eradication, leading to decreased acid secretion because of their reduced cell mass. The half life of parietal cells in mice is reported to be 23 days and may be even longer in humans. ${ }^{28}$ According to a previous study on a patient with curatively resected gastrinoma, maximal acid output decreased three to six months after the tumour resection. ${ }^{29}$ This result suggests that it will take several months for acid secretion to decrease through removal of the trophic effect of gastrin as seen in the present study. However, in patients with GU, hypergastrinaemia may be caused not only by $H$ pylori itself $^{30}{ }^{31}$ but also by compensation for lower acid secretion. ${ }^{32}$ Hence the decrease in plasma gastrin after $H$ pylori eradication may be partly due to a concomitant increase in acid secretion. However, the latter mechanism seems less likely because the changes in plasma gastrin before and after $H$ pylori eradication were similar between the DU and GU groups, in spite of the different behaviour with respect to acid secretion in the two groups.

Interestingly, the decrease in acid secretion observed between one and seven months after eradication was somewhat less in patients with GU than in those with DU, and, in fact, in a small number of patients with GU, acid secretion increased during this period. A recent study reported that, in patients with fundic atrophic gastritis, improvement in acid secretion coincided with resolution of mucosal atrophy. ${ }^{33}$ As mucosal atrophy was greater in patients with GU than in those with DU in this study, it is possible that a reason for the slower decrease in acid secretion in the GU group in that period is that the beneficial effect of $H$ pylori eradication - that is, a reduction in acid secretion by long term normalisation of plasma gastrin-was partially cancelled out by an increase in acid secretion as the result of resolution of gastric atrophy. Consequently, during the seven month follow up period after $H$ pylori eradication, the mean EGT value decreased by $23 \%$ in patients with DU, whereas it increased by $48 \%$ in those with GU, compared with the pretreatment values, resulting in the EGT values of both groups being in the same range as $H$ pylori negative normal controls.

The nature of long term changes in gastrin stimulated acid secretion after $H$ pylori eradication in patients with DU remains controversial. $^{4-11}$ Parente and colleagues ${ }^{7}$ and Harris and colleagues ${ }^{8}$ have reported that it was decreased six months after eradication, and Laszewicz and colleagues ${ }^{11}$ have reported it to be decreased one year after eradication, findings in agreement with the present study. On the other hand, El-Omar and colleagues ${ }^{9}$ and Gisbert and colleagues ${ }^{10}$ have reported no change at five months and one year after eradication. In the study of El-Omar et al, gastrin releasing peptide stimulated acid output was decreased by $80 \%$ one year after eradication, but the gastrin stimulated acid output had not changed significantly. However, the rate of the decrease in gastrin stimulated acid output after $H$ pylori eradication, reported to be $16 \%$ by Parente et $a l,{ }^{7} 33 \%$ by Harris et $a l,{ }^{8}$ and $23 \%$ in our study, was small compared with the changes in gastrin releasing peptide stimulated output. Therefore a larger population would be needed to detect the slight difference in gastrin stimulated acid output before and after $\mathrm{H}$ pylori eradication in patients with DU. Gisbert and colleagues ${ }^{10}$ also did not find significant differences in gastrin stimulated acid output before and after $H$ pylori eradication, although they studied a relatively large sample of 26 patients with DU. However, because in their study, acid output in patients with $H$ pylori infection was not compared with that of $H$ pylori negative normal controls, it is unclear whether those patients had gastric acid hypersecretion before $H$ pylori eradication. In fact, maximal gastrin stimulated acid output before eradication was somewhat lower in their study than in other reports. ${ }^{6-9}$ The most likely reason for the difference was that more than half of the patients with DU had body gastritis, which has been shown to inhibit acid secretion reversibly in oxyntic mucosa, ${ }^{17-19}$ whereas in general, most patients with DU are considered to have antrum predominant gastritis. ${ }^{2021}$

There have been few reports ${ }^{11}$ on changes in acid secretion before and after $H$ pylori eradication in patients with GU. This is the first study showing that stimulated acid output increases after $H$ pylori eradication in patients with GU, which supports the report of Furuta and colleagues $^{34}$ that gastric juice $\mathrm{pH}$ in patients with GU decreases after eradication. However, it is possible that the rate of this increase in acid secretion varies from subject to subject, because acid secretion in patients with GU varies greatly depending on the anatomical location of the ulcers. In particular, in patients with ulcers in the antrum, which are associated with hypersecretion, ${ }^{15}{ }^{16}$ acid secretion may decrease after $H$ pylori eradication as in patients with DU. In the $H$ pylori positive patients with GU in this study, elevated plasma gastrin may have increased acid secretion through a direct effect or through a trophic effect on parietal cells and/or enterochromaffin-like cells. How ever, this effect may be neutralised by coexisting gastritis of the body, which impaired the acid secretory response to increased gastrin. The net effect was to leave these patients with low acid secretion. In patients with GU, acid secretion showed a biphasic response to eradication of $H$ pylori. Initially there was a rapid increase in acid secretion concomitant with resolution of body gastritis while the trophic effect remained active. Subsequently a late decrease in acid secretion occurred when the trophic effect on oxyntic mucosa was removed. 
It has been shown that eradication of $H$ pylori appreciably decreases DU relapse rates, ${ }^{1-3}$ and our findings support the concept that this may be related, in part, to decreased acid secretion. However, eradication of $H$ pylori also decreases GU relapse rates, ${ }^{23}$ in spite of the accompanying increase in acid secretion. The great success of specific antisecretory agents such as $\mathrm{H}_{2}$ receptor antagonists in the treatment of peptic ulcers has been considered to be evidence that gastric acidity plays a central role in the pathogenesis of peptic ulcer. However, the role of antisecretory drugs in preventing GU relapse seems not to be as important as in DU. ${ }^{35-37}$ Although some studies $^{38-40}$ have shown that such drugs exert a considerable effect, other studies ${ }^{41}{ }^{42}$ have concluded that they have little or no influence on GU recurrence. The latter findings suggest that, in patients with GU, mucosal defence factors are more important for ulcer recurrence than detrimental factors such as acid secretion, compared with patients with DU.

Considering the preceding studies and our results together, $H$ pylori eradication may decrease the rate of relapse in GU by enhancing defence factors, possibly by permitting the resolution of mucosal inflammation. This improved mucosal defence may outweigh the effect of increased acid secretion.

In conclusion, gastrin stimulated maximal acid secretion is abnormal in patients with $H$ pylori infection who have peptic ulcer diseases. Patients with DU display hypersecretion and patients with GU display hyposecretion compared with $H$ pylori negative normal controls. This secretory disturbance is resolved fully after eradication of $H$ pylori. These differing effects of $H$ pylori on acid secretion may be related to the distribution of gastritis within the stomach.

1 Forbes GM, Glaser ME, Cullen DJE, et al. Duodenal ulcer treated with Helicobacter pylori eradication: seven-year treated with Helicobacter pylori

2 Graham DY, Lew GM, Klein PD, et al. Effect of treatment of Helicobacter pylori infection on the long-term recurrence of gastric or duodenal ulcer. Ann Intern Med 1992;116:705-8.

3 Chiba N, Rao BV, Rademaker JW, et al. Meta-analysis of the efficacy of antibiotic therapy in eradicating Helicobacter pylori. Am $\mathcal{F}$ Gastroenterol 1992;87:1716-27.

4 Levi S, Beardshall K, Desa LA, et al. Campylobacter pylori, gastrin, acid secretion and duodenal ulcers. Lancet 1989;2 613.

5 McColl KEL, Fullarton GM, Ghittajalu R, et al. Plasma gastrin, day time intragastric $\mathrm{pH}$, and nocturnal acid output before and at 1 and 7 months after eradication of Helicobacter pylori in duodenal ulcer subjects. Scand $\mathcal{f}$ Gastroentrol 1991;26:339-46.

6 Moss SF, Calam J. Acid secretion and sensitivity to gastrin in patients with duodenal ulcer: effect of eradication of in patients with duodenal ulcer: effect

7 Parente F, Maconi G, Sangaletti O, et al. Behaviour of acid Parente F, Maconi G, Sangaletti O, et al. Behaviour of acid
secretion, gastrin release, serum pepsinogen, and gastric secretion, gastrin release, serum pepsinogen, and gastric
emptying of liquids over six months from eradication of emptying of liquids over six months from eradication of Helicobacter pylori on duodenal
led study. Gut 1995;37:210-15.

led study. Gut 1995;37:210-15.
8 Harris AW, Gummett PA, Misiewicz JJ, et al. Eradication of Helicobacter pylori in patients with duodenal ulcer lowers basal and peak acid outputs to gastrin releasing peptide and pentagastrin. Gut 1996;38:663-7

9 El-Omar EM, Penman ID, Ardill JES, et al. Helicobacter pylori infection and abnormalities of acid secretion in patients with duodenal ulcer disease. Gastroenterology 1995;109:681-91.

10 Gisbert JP, Boixeda D, Vila T, et al. Basal and stimulated gastrin levels and gastric acid output five months after therapy for Helicobacter pylori eradication in duodenal ulcer patients. F Clin Gastroenterol 1996;22:90-5.

11 Laszewicz W, Zaremba Woroniecka A, Gabryelewicz A Helicobacter pylori infection and gastric secretion in duodenal and gastric ulcer patients: the effect of duodenal and gastric ulcer patients: the effect of
eradication after one year. $\mathcal{F}$ Physiol Pharmacol 1997;48: 353-64.
12 Iijima $\mathrm{K}$, Ohara $\mathrm{S}$, Sekine $\mathrm{H}$, et al. A new endoscopic method of gastric acid secretory testing. Am f Gastroenterol 1998;93:2113-18.

13 Misiewicz JJ, Tytgat GN, Goodwin CS, et al. The Sydney System; a new classification of gastritis. Working Party Reports 1990;1-10.

14 Ohara S, Kato M, Asaka M, et al. Studies of 13C-urea breath test for diagnosis of Helicobacter pylori infection in Japan. 7 Gastroenterol 1998;33:6-13.

15 Brooks FP. Tests related to the stomach. In: Bockus HL, ed. Gastroenterology. 4th ed. Philadelphia: WB Saunders, 1985: $367-77$.

16 Johnson HD. Gastric ulcer: classification, blood group characteristics, secretion patterns and pathogenesis. Ann Surg 1965;162:996-1004.

17 Gutierrez O, Melo M, Segura AM, et al. Cure of Helicobacter pylori infection improves gastric acid secretion in patients with corpus gastritis. Scand $\mathcal{f}$ Gatroenterol 1997;32:664-8.

18 El-Omar EM, Oien K, El-Nujumi A, et al. Helicobacter pylori infection and chronic gastric acid hyposecretion. Gastroenterology 1997;113:15-24

19 Yasunaga Y, Shinomura Y, Kanayama S, et al. Improved fold width and increased acid secretion after eradication of the organism in Helicobacter pylori associated enlarged fold gastritis. Gut 1994;35:1571-4.

20 Louw JA, Flalck V, van Rensburg C, et al Distribution of Helicobacter pylori colonisation and associated gastric inflammatory changes: difference between patients with duodenal and gastric ulcers. F Clin Pathol 1993;46: 754-6.

21 Van der Hulst RWM, Tytgat GNJ. Helicobacter pylori and peptic ulcer disease. Scand f Gastroenterol 1996;31(suppl 220): $10-18$

22 Wallace JL, Cucala M, Mugridge K, et al. Secretagoguespecific effects of interleukin-1 on gastric acid secretion. Am 7 Physiol 199;261:G559-64.

23 Noach LA, Bosma NB, Jansen J, et al. Mucosal tumor necrosis factor-alpha, interleukin-1 beta, and interleukin-8 production in patients with Helicobacter pylori infection. Scand $\mathcal{F}$ Gastroenterol 1994;29:425-9.

24 Cave DR, Vargas M. Effect of a Campylobacter pylori protein on acid secretion by parietal cells. Lancet 1989;2:187-9.

25 Willems G, Lehy T. Radioautographic and quantitative studies on parietal and peptic cell kinetics in the mouse. Gastroenterology 1975;69:416-26.

26 Johnson LR. The trophic action of gastrointestinal hormones. Gastroenterology 1976;70:278-82

27 Bechi P, Romagnoli P, Bacci S, et al. Helicobacter pylori and duodenal ulcer: evidence for histamine pathway-involving link. Am f Gastroenterol 1996;91:2338-43.

28 Ragins H, Wincze F, Liu SM, et al. The origin and survival of gastric parietal cells in the mouse. Anat Rec 1968;162: 99-110.

29 Pisegna JR, Norton JA, Slimak GG, et al. Effects of curative gastrinima resection on gastric secretory function and antisecretory drug requirement in the Zollinger-Ellison syndrome. Gastroenterology 1992;102:767-78.

30 Levi S, Beardshall K, Haddad G, et al. Campylobacter pylori and duodenal ulcers: the gastrin link. Lancet 1989;i: $1167-8$

31 Weigert N, Schaffer K, Schusdziarra V, et al. Gastrin secretion from primary cultures of rabbit antral G cells: stimulation by inflammatory cytokines. Gastroenterology 1996;110: $147-54$.

32 Walsh JH, Richardson CT, Fordtran JS. pH dependence of acid secretion and gastrin release in normal and ulcers subjects. F Clin Invest 1975;55:462-8.

33 Tucci A, Biasco G, Paparo GF. Effect of eradication of Helicobacter pylori in patients with fundic atrophic gastritis. N Engl F Med 1997;336:957-8.

34 Furuta T, Baba S, Takashima M, et al. Effect of Helicobacter pylori infection on gastric juice $\mathrm{pH}$. Scand $\mathcal{F}$ Gastroenterol 1998;33:357-63.

35 Burland WL, Hawkins BW, Beresford J. Cimetidine treatment for prevention of recurrence of duodenal ulcer: an international collaborative study. Postgrad Med $\mathcal{f}$ 1980;56:173-6.

36 Gough KR, Bardhan KD, Crowe JP, et al. Ranitidine and cimetidine in prevention of duodenal ulcer relapse. Lancet 1984;2:659-62.

37 Lee F, Reed PI, Crowe JP, et al. Acute treatment of duodenal ulcer: a multicentre study to compare ranitidine $150 \mathrm{mg}$ twice daily with ranitidine $300 \mathrm{mg}$ once at night. Gut 1986; 27:1091-5.

38 Hentschel E, Schutze K, Weiss W, et al. Effect of cimetidine treatment in the prevention of gastric ulcer relapse: a one year double blind multicentre study. Gut 1983;24:858-6.

39 Machell RJ, Farthing MJG, Ciclitira PJ, et al. Cimetidine in the prevention of gastric ulcer relapse. Postgrad Med $\mathcal{F}$ 1979;55:393-5

40 Birger JK, Mollmann KM, Rahbek I, et al. Prophylactic effect of cimetidine in gastric ulcer patients. Scand $f$ Gastroenterol 1979;14:175-6.

41 Barr GD, Kang JY, Canalese J, et al. A two-year prospective controlled study of maintenance cimetidine and gastric ulcer. Gastroenterology 1983;85:100-4.

42 Tatsuta M, Iishi H, Okuda S. Effects of cimetidine on the healing and recurreence of duodenal and gastric ulcers. Gut 1986;27:1213-18 